\title{
Use of oxidized regenerated cellulose to achieve hemostasis during laparoscopic cholecystectomy: a retrospective cohort analysis
}

\author{
Emilia Masci, Giuseppe Faillace and Mauro Longoni
}

\begin{abstract}
Objective: Laparoscopic cholecystectomy is the first-choice treatment for symptomatic cholelithiasis. Though generally safe, this procedure is not without complications, with bleeding the most frequent cause of conversion to open cholecystectomy. Oxidized regenerated cellulose (ORC) added to conventional hemostatic strategies, is widely used to control bleeding during surgery despite limited evidence supporting its use. This retrospective study analyzed patients undergoing laparoscopic cholecystectomy in an Italian center over a 16-month period, between October 2014 and February 2016, who experienced uncontrollable bleeding despite the use of conventional hemostatic strategies, requiring the addition of ORC gauze (Emosist $\left.{ }^{\circledR}\right)$.
\end{abstract}

Results: Of the 530 patients who underwent laparoscopic cholecystectomy, 24 (4.5\%) had uncontrollable bleeding from the liver bed. Of these, $62.5 \%$ had acute cholecystitis and 33.3\% chronic cholecystitis; 1 patient was diagnosed with gallbladder carcinoma, postoperatively. Most patients had comorbidities, 16.7\% had liver cirrhosis, and 37.5\% used oral anticoagulants. The application of ORC rapidly controlled bleeding in all patients. Patients were discharged after a mean duration of 2.2 days. ORC was easy to use and well tolerated. Bleeding complications remain a relevant issue in laparoscopic cholecystectomy. ORC was able to promptly stop bleeding not adequately controlled by conventional methods and appears, therefore, to be a useful hemostat.

Keywords: Bleeding, Laparoscopic cholecystectomy, Hemorrhage, Hemostasis, Oxidized regenerated cellulose, Topical hemostat

\section{Introduction}

Laparoscopic cholecystectomy has been the first-choice treatment for symptomatic cholelithiasis, and is among the most frequently performed interventions $[1,2]$. Compared with open surgery, laparoscopic cholecystectomy has important advantages, including reduced morbidity and mortality, shorter hospital stay, faster return to daily activities, better cosmetic results, and reduced postoperative pain [3-5]. Laparoscopic cholecystectomy can also be offered to patients with acute cholecystitis [6-8] or cirrhosis, two conditions traditionally considered as

*Correspondence: emilia.masci@asst-nordmilano.it Division of General Surgery, Ospedale Edoardo Bassini, ASST Nord Milano, Via Gorki 50, 20092 Cinisello Balsamo, MI, Italy contraindications for laparoscopic surgery due to an increased risk of complications [9-11].

Despite its generally favorable safety profile, laparoscopic cholecystectomy is not without complications [12], and rates of up to $10 \%$ for conversion to open cholecystectomy are still reported [13]. Bile duct injuries are the most feared complication due to substantial morbidity [14-16]. Bleeding complications, during surgery or postoperatively, are also relevant in laparoscopic cholecystectomy, but less attention has been devoted to them [14]. The lack of a generally accepted classification of bleeding events may have contributed to this situation.

Various tools and procedures are currently available to ensure hemostasis during surgical interventions 
[17]. Conventional strategies include electrocautery and suture ligation [17], however, the prolonged use of bipolar or monopolar electrocautery in laparoscopic cholecystectomy has been associated with damage to parenchymal tissue and postoperative bile leakage, and should be avoided [18]. Several topical hemostats including oxidized regenerated cellulose (ORC), gelatin, collagen, thrombin, fibrin sealants, and synthetic sealants are also available for a variety of clinical settings $[17,19]$.

ORC, developed over 60 years ago, is a plant-derived, passive hemostat that promotes hemostasis by providing a matrix for platelet adhesion and aggregation. It is available in various fabric formats allowing for multiple applications, can conform to irregular surfaces and hardto-reach sites, adheres easily to bleeding surfaces, and is suitable for laparoscopic cholecystectomy [20]. ORC is rapidly absorbed by hydrolysis within 7-20 days depending on the amount used. [21, 22]. ORC has bactericidal properties attributable to its local $\mathrm{pH}$-lowering effect against a wide spectrum of pathogens, including methicillin-resistant Staphylococcus aureus [23, 24]. ORC has been evaluated in prospective randomized studies only recently, despite its widespread use in surgical practice [25-27], hence evidence-based information on its optimal use is lacking.

This retrospective analysis reports on our experience with ORC for hemostasis in patients undergoing laparoscopic cholecystectomy who experienced uncontrollable bleeding despite the use of conventional hemostatic strategies.

\section{Main text \\ Methods \\ Study design and patients}

This was a retrospective analysis of data from patients who underwent laparoscopic cholecystectomy at the Division of General Surgery of the Edoardo Bassini Hospital, Cinisello Balsamo, Italy, between October 2014 and February 2016. The primary objective was to describe the use and outcomes of topical hemostasis with ORC in patients with difficult-to-treat bleeding during laparoscopic cholecystectomy. Difficult-to-treat bleeding was assessed based on the bleeding flow and depth during laparoscopic cholecystectomy. If bleeding continued uncontrolled for a few minutes despite the use of conventional hemostatic techniques (monopolar or bipolar electrocautery), ORC gauze was applied on the liver bed to avoid prolonged use of electrocautery in order to prevent parenchymal tissue damage. Conventional hemostatic techniques were standardized and consistent across all patients. Clip or suture blind application during major bleeding should be avoided due to high risk of associated vascular and biliary damage.
Data were extracted from the surgical records of the center, including information related to hemostatic procedures performed during the intervention. Patients who experienced bleeding from the liver bed that could not be adequately controlled by conventional hemostatic techniques, and required the addition of a topical hemostatic agent, were included. The hemostatic agent used was ORC gauze (Emosist ${ }^{\circledR}$, Mascia Brunelli, Milano, Italy). Patients, who required conversion to open surgery because of major bleeding (i.e., involving the major branch of the middle hepatic vein), or bile duct injury, were not included in the analysis. The following data were extracted: demographic characteristics; type of gallbladder disease; comorbidities; risk factors for bleeding (cirrhosis, use of anticoagulants); need for transfusions; need for a new intervention; duration of hospital stay; hospital readmission. The analysis was performed after study approval by the local Institutional Review Board P.O. Edoardo Bassini, ASST Nord Milano. All patients provided their written informed consent for being included in this study.

\section{Interventions}

Diagnostic procedures and cholecystectomy were performed according to current national and international guidelines for cholelithiasis management and laparoscopic cholecystectomy [1, 2, 9, 28]. Diagnosis of acute or chronic cholecystitis was based on medical history, physical examination, laboratory tests, and ultrasound imaging. In both early and elective laparoscopic cholecystectomy, the pneumoperitoneum was established by inserting a Veress needle in the umbilical region followed by the introduction of four trocars. Adhesions, when present, were severed to ensure the optimal exposure of the surgery field and identification of the cystic artery and cystic duct in the Calot's triangle. Cystic artery and cystic duct were ligated with clips before division, and dissection of the gallbladder from the liver bed was performed using a monopolar electrocautery hook.

During the procedure, hemostasis was ensured by electrocautery (bipolar clamp), if needed. In patients with persistent bleeding despite bipolar electrocautery, a $10 \times 20 \mathrm{~cm}$ folded piece of ORC gauze was placed in the liver bed. After achievement of bleeding control, the liver bed was monitored for at least $5 \mathrm{~min}$ and blood clots were removed using an irrigation-aspiration system. Although we routinely adopt a no-drain policy for laparoscopic cholecystectomy, patients with persistent bleeding during surgery received a sub-hepatic drainage. After the intervention, patients were kept under observation for at least $48 \mathrm{~h}$ before hospital discharge.

Blood samples were taken preoperatively and prothrombin time (PT), activated partial thromboplastin 
time, international normalized ratio (INR) and platelets were measured in all patients undergoing laparoscopic cholecystectomy. Patients receiving anticoagulants at presentation and undergoing elective laparoscopic cholecystectomy, discontinued oral anticoagulants before surgery and switched to low molecular weight heparin. Patients on oral anticoagulants needing early laparoscopic cholecystectomy due to acute cholecystitis received transfusions of fresh frozen plasma, intravenous vitamin $\mathrm{K}$ and/or prothrombin complex concentrate, according to clinical condition. No blood samples were taken intra-operatively as it was presumed that all hemostatic parameters were within normal limits in all patients.

\section{Statistical methods}

Data were analyzed by descriptive statistics and summarized as percentages or mean values.

\section{Results}

In the 16-month period, 530 patients underwent laparoscopic cholecystectomy in our center. The use of ORC gauze during surgery was required in 24 (4.5\%) patients [10 males and 14 females, median age 58 years (range 18-84)], as conventional methods failed to adequately control bleeding from the liver bed. In all 24 cases, effective hemostasis was typically achieved between 3 and $7 \mathrm{~min}$ from application of the ORC gauze. Patients' demographic and preoperative characteristics are shown in Table 1 . The majority of patients $(15 / 24,62.5 \%)$ underwent early laparoscopic cholecystectomy due to acute cholecystitis, whereas the intervention was elective for 8 patients (33.3\%) with chronic cholecystitis; 1 patient who underwent laparoscopic cholecystectomy for suspected chronic cholecystitis was postoperatively diagnosed with advanced gallbladder cancer (pT2). Among patients with chronic cholecystitis, 3 (37.5\%) had a history of endoscopic retrograde cholangiopancreatography

Table 1 Patient demographic and clinical characteristics ( $N=24)$

\begin{tabular}{lc}
\hline Age, years (range) & $58(18-84)$ \\
Female, $\mathrm{n}(\%)$ & $14(58.3)$ \\
Male, $\mathrm{n}(\%)$ & $10(41.7)$ \\
Gallbladder disease, $\mathrm{n}(\%)$ & \\
$\quad$ Acute cholecystitis & $15(62.5)$ \\
Chronic cholecystitis & $8(33.3)$ \\
$\quad$ Gallbladder carcinoma & $1(4.2)$ \\
With comorbidities, $\mathrm{n}(\%)$ & $20(83.3)$ \\
With liver cirrhosis, $\mathrm{n}(\%)$ & $4(16.7)$ \\
In treatment with oral anticoagulants, $\mathrm{n}(\%)$ & $9(37.5)$ \\
\hline
\end{tabular}

plus sphincterotomy for biliary pancreatitis. In 2 of the 8 patients with chronic cholecystitis, the procedure was complicated by the presence of scarred tissue. In these patients, the gallbladder was intentionally ruptured and partially removed; the portion that could not be dissected was left in the liver bed. Nonetheless, the application of ORC to the liver bed after dissection provided adequate hemostasis with no need for hemostatic suture in the liver bed and, more importantly, for conversion to open cholecystectomy. Most patients (20/24, 83.3\%) had comorbidities including hypertension, heart disease, diabetes, chronic renal insufficiency, and chronic liver disease. Four patients (16.7\%) had liver cirrhosis, which was hepatitis $B$ virus-related in 3 patients and hepatitis $C$ virus-related in 1 patient. In nine patients (37.5\%) receiving oral anticoagulants, laparoscopic cholecystectomy was performed in the presence of normal values of PT and INR.

Two patients $(8.3 \%)$ who had undergone emergency laparoscopic cholecystectomy due to acute cholecystitis, required blood transfusions for $48 \mathrm{~h}$ postoperatively. The mean duration of hospital-stay after laparoscopic cholecystectomy was 2.2 days for the overall population. There were no reoperations and no readmissions after discharge. Diagnostic procedures performed postoperatively and at hospital discharge did not detect any abscess or granuloma.

\section{Discussion}

Intraoperative bleeding remains a relevant complication in laparoscopic cholecystectomy. In line with reported incidence rates [14, 29], $4.5 \%$ of patients in this retrospective study experienced a bleeding event that could not be controlled by conventional hemostatic strategies. Our data show that the use of ORC provided adequate hemostasis during the intervention preventing conversion to open surgery, or prolonged and potentially damaging use of conventional hemostatic strategies, such as electrocautery. In our experience, the laparoscopic application of ORC gauze to the liver bed was easy to perform and resulted in effective bleeding control within minutes.

Recently, fewtrials and observational reports have tried to define the efficacy and safety of ORC and other topical hemostatic agents in a variety of surgery settings, including hepatectomy [30,31], neurosurgery [25], gynecologic surgery [32, 33], nephrectomy [34, 35], and thyroid surgery $[36,37]$. To our knowledge, this is the first study to investigate the efficacy and safety of ORC gauze in laparoscopic cholecystectomy.

The application of ORC gauze in our patients was well tolerated, without adverse events. However, ORC is limited by its potential to swell causing pressure on adjacent tissues and organs, hence it should be removed after 
surgery when used in proximity of sensitive areas, especially in neurosurgery [25]. Rarely, foreign-body reactions to ORC may occur, which can be erroneously interpreted as postoperative abscesses on computed tomography (CT) [32, 33, 38-42]. Therefore, the use and location of ORC should be reported in the patient chart and notified to other treating clinicians, to avoid misinterpretation of CT findings and unnecessary diagnostic interventions [32, 38].

Perhaps not surprisingly, most patients with uncontrolled bleeding in our study were those undergoing early laparoscopic cholecystectomy due to acute cholecystitis. Previously, acute cholecystitis was considered a contraindication for laparoscopic intervention, as the inflammatory environment leads to neoangiogenesis in the liver bed and to increased risk of bleeding. In all our patients with acute cholecystitis and uncontrolled bleeding with traditional hemostatic methods, application of ORC gauze to the bleeding site successfully stopped bleeding.

One-third of our patients with uncontrolled bleeding had chronic cholecystitis. In chronic forms of gallbladder disease, especially if previously treated with conservative therapies including antibiotics and reduced food intake, fibrotic and scarred tissue in the liver bed complicates gallbladder dissection and increases the risk of bleeding. Our results show ORC gauze was effective in ensuring adequate bleeding control in these chronic cases, including two cases involving intentional gallbladder rupture where the portion that could not be removed without high risk of vascular and biliary injury was left in the liver bed.

In uncomplicated laparoscopic cholecystectomy, the postoperative use of an abdominal drain is generally not recommended, lacking conclusive evidence of a benefit [9]. In all 24 patients of this analysis, an abdominal sub-hepatic drainage was implanted postoperatively, in accordance with the protocol of our center recommending the use of a drain in patients at risk of bleeding or of biliary leakage. Absorbed hemostatic material can visibly alter the color and consistency of the drained fluid, which can appear darker and corpusculated, leading to a wrong diagnosis of bile leakage or abscess. Also for this reason the use of ORC should be notified to clinicians treating the patient after cholecystectomy.

\section{Conclusions}

In high-risk patients undergoing laparoscopic cholecystectomy with bleeding not adequately controlled by conventional techniques, ORC was easy to use and effective in ensuring adequate hemostasis. The role of topical hemostatic agents, including ORC, should be further investigated in prospective randomized studies with larger sample sizes in order to understand their potential and to optimize their use.

\section{Limitations}

The retrospective nature and small sample size of this study limit generalization of our data. Nevertheless we believe the present analysis provides useful information regarding the use of ORC in a heterogeneous population typically encountered in clinical practice, and in laparoscopic cholecystectomy interventions at increased risk of bleeding complications.

\section{Abbreviations \\ CT: computed tomography; ORC: oxidized regenerated cellulose. \\ Authors' contributions \\ EM, GF and ML contributed equally to the conception and design of the study and to the collection, analysis, and interpretation of the data. EM performed the literature search and was the major contributor in writing manuscript. EM, GF and ML critically revised the manuscript. All authors read and approved the final manuscript.}

\section{Acknowledgements}

The Authors thank Dr. Melanie Gatt (Ph.D.), an independent medical writer, who provided editorial assistance on behalf of Springer Healthcare Communications.

\section{Competing interests \\ The authors declare that they have no competing interests.}

\section{Availability of data and materials}

All data generated or analyzed during this study are included in this published article.

\section{Consent for publication}

Not applicable.

\section{Ethics approval and consent to participate}

This study was approved by the local Institutional Review Board P.O. Edoardo Bassini, ASST Nord Milano. Written informed consent was obtained from all patients for being included in this study.

\section{Funding}

Editorial assistance was funded by Mascia Brunelli Spa. Funding sources had no role in the design of this study, no role in collection, analysis, and interpretation of data or in writing the manuscript.

\section{Publisher's Note}

Springer Nature remains neutral with regard to jurisdictional claims in published maps and institutional affiliations.

Received: 23 January 2018 Accepted: 30 March 2018

Published online: 11 April 2018

References

1. Agresta F, Ansaloni L, Baiocchi GL, Bergamini C, Campanile FC, Carlucci $\mathrm{M}$, et al. Laparoscopic approach to acute abdomen from the Consensus Development Conference of the Societa Italiana di Chirurgia Endoscopica e nuove tecnologie (SICE), Associazione Chirurghi Ospedalieri Italiani (ACOI), Societa Italiana di Chirurgia (SIC), Societa Italiana di Chirurgia d'Urgenza e del Trauma (SICUT), Societa Italiana di Chirurgia nell'Ospedalita Privata (SICOP), and the European Association for Endoscopic Surgery (EAES). Surg Endosc. 2012;26:2134-64.

2. Williams EJ, Green J, Beckingham I, Parks R, Martin D, Lombard M, et al. Guidelines on the management of common bile duct stones (CBDS). Gut. 2008;57:1004-21 
3. Barkun JS, Barkun AN, Meakins JL. Laparoscopic versus open cholecystectomy: the Canadian experience. The McGill Gallstone Treatment Group. Am J Surg. 1993;165:455-8.

4. Dolan JP, Diggs BS, Sheppard BC, Hunter JG. The national mortality burden and significant factors associated with open and laparoscopic cholecystectomy: 1997-2006. J Gastrointest Surg. 2009;13:2292-301.

5. Keus F, de Jong JA, Gooszen HG, van Laarhoven CJ. Laparoscopic versus open cholecystectomy for patients with symptomatic cholecystolithiasis. Cochrane Database Syst Rev. 2006:(4):CD006231.

6. Johansson M, Thune A, Nelvin L, Stiernstam M, Westman B, Lundell L. Randomized clinical trial of open versus laparoscopic cholecystectomy in the treatment of acute cholecystitis. Br J Surg. 2005;92:44-9.

7. Kiviluoto T, Siren J, Luukkonen P, Kivilaakso E. Randomised trial of laparoscopic versus open cholecystectomy for acute and gangrenous cholecystitis. Lancet. 1998;351:321-5.

8. Sauerland S, Agresta F, Bergamaschi R, Borzellino G, Budzynski A, Champault G, et al. Laparoscopy for abdominal emergencies: evidence-based guidelines of the European Association for Endoscopic Surgery. Surg Endosc. 2006;20:14-29.

9. Society of American Gastrointestinal and Endoscopic Surgeons. Guidelines for the clinical application of laparoscopic biliary tract surgery. http://www.sages.org/publications/guidelines/guidelines-for-the-clini cal-application-of-laparoscopic-biliary-tract-surgery/. Accessed 27 Sept 2017.

10. Lledo JB, Ibanez JC, Mayor LG, Juan MB. Laparoscopic cholecystectomy and liver cirrhosis. Surg Laparosc Endosc Percutan Tech. 2011;21:391-5.

11. Puggioni A, Wong LL. A metaanalysis of laparoscopic cholecystectomy in patients with cirrhosis. J Am Coll Surg. 2003;197:921-6.

12. Shamiyeh A, Wayand W. Laparoscopic cholecystectomy: early and late complications and their treatment. Langenbecks Arch Surg. 2004:389:164-71.

13. Lengyel BI, Azagury D, Varban O, Panizales MT, Steinberg J, Brooks DC, et al. Laparoscopic cholecystectomy after a quarter century: why do we still convert? Surg Endosc. 2012;26:508-13.

14. Kaushik R. Bleeding complications in laparoscopic cholecystectomy: incidence, mechanisms, prevention and management. J Minim Access Surg. 2010;6:59-65.

15. Nuzzo G, Giuliante F, Giovannini I, Ardito F, D'Acapito F, Vellone M, et al. Bile duct injury during laparoscopic cholecystectomy: results of an Italian national survey on 56,591 cholecystectomies. Arch Surg. 2005;140:986-92.

16. Shea JA, Healey MJ, Berlin JA, Clarke JR, Malet PF, Staroscik RN, et al. Mortality and complications associated with laparoscopic cholecystectomy. A meta-analysis. Ann Surg. 1996;224:609-20.

17. Sundaram CP, Keenan AC. Evolution of hemostatic agents in surgical practice. Indian J Urol. 2010;26:374-8.

18. Kockerling F, Schneider C, Reymond MA, Hohenberger W. Controlling complications in laparoscopic cholecystectomy: diffuse parenchyma hemorrhage in the liver parenchyma. Zentralbl Chir. 1997;122:405-8.

19. Emilia M, Luca S, Francesca B, Luca B, Paolo S, Giuseppe F, et al. Topical hemostatic agents in surgical practice. Transfus Apher Sci. 2011;45:305-11.

20. Kent RB 3rd, Naughton MJ. Hemostasis of the gallbladder fossa during laparoscopic cholecystectomy. Surg Laparosc Endosc. 1991;1:104-5.

21. Dimitrijevich SD, Tatarko M, Gracy RW, Linsky CB, Olsen C. Biodegradation of oxidized regenerated cellulose. Carbohydr Res. 1990;195:247-56.

22. Spanel-Borowski K. The chick chorioallantoic membrane as test system for biocompatible materials. Res Exp Med (Berl). 1989;189:69-75.
23. Dineen P. Antibacterial activity of oxidized regenerated cellulose. Surg Gynecol Obstet. 1976;142:481-6.

24. Spangler D, Rothenburger S, Nguyen K, Jampani H, Weiss S, Bhende S. In vitro antimicrobial activity of oxidized regenerated cellulose against antibiotic-resistant microorganisms. Surg Infect (Larchmt). 2003:4:255-62.

25. Keshavarzi S, MacDougall M, Lulic D, Kasasbeh A, Levy M. Clinical experience with the surgicel family of absorbable hemostats (oxidized regenerated cellulose) in neurosurgical applications: a review. Wounds. 2013:25:160-7.

26. Sharma JB, Malhotra M, Pundir P. Laparoscopic oxidized cellulose (surgicel) application for small uterine perforations. Int J Gynaecol Obstet. 2003:83:271-5

27. Theuer CP, Imagawa DK. Use of knitted oxidized cellulose (Nu-knit) for the definitive packing of grade III liver fracture. Injury. 1999;30:137-40.

28. Yamashita Y, Takada T, Kawarada Y, Nimura Y, Hirota M, Miura F, et al. Surgical treatment of patients with acute cholecystitis: Tokyo Guidelines. J Hepatobiliary Pancreat Surg. 2007;14:91-7.

29. Opitz I, Gantert W, Giger U, Kocher T, Krahenbuhl L. Bleeding remains a major complication during laparoscopic surgery: analysis of the SALTS database. Langenbecks Arch Surg. 2005:390:128-33.

30. Genyk Y, Kato T, Pomposelli JJ, Wright JK Jr, Sher LS, Tetens V, et al. Fibrin sealant patch (TachoSil) vs oxidized regenerated cellulose patch (surgicel original) for the secondary treatment of local bleeding in patients undergoing hepatic resection: a randomized controlled trial. J Am Coll Surg. 2016;222:261-8.

31. Wang Z, Liao BY, Qiu SJ, Sun HC, Yang XR, Zhou J, et al. Oxidized regenerated cellulose reduces the amount of fluid drainage after liver resection: a randomized prospective clinical trial. Hepatogastroenterology. 2015:62:951-4.

32. Tam T, Harkins G, Dykes T, Gockley A, Davies M. Oxidized regenerated cellulose resembling vaginal cuff abscess. JSLS. 2014:18:353-6.

33. Zhang F, Bonidie MJ, Ventrelli SM, Furlan A. Intraovarian oxidized cellulose (surgicel) mimicking acute ovarian pathology after recent pelvic surgery. Radiol Case Rep. 2015;10:39-41.

34. Hong YM, Loughlin KR. The use of hemostatic agents and sealants in urology. J Urol. 2006;176:2367-74

35. van Dijk JH, Pes PL. Haemostasis in laparoscopic partial nephrectomy: current status. Minim Invasive Ther Allied Technol. 2007;16:31-44.

36. Amit M, Binenbaum Y, Cohen JT, Gil Z. Effectiveness of an oxidized cellulose patch hemostatic agent in thyroid surgery: a prospective, randomized, controlled study. J Am Coll Surg. 2013;217:221-5.

37. Tartaglia N, Di Lascia A, Lizzi V, Cianci P. Fersini A, Ambrosi A, et al. Haemostasis in thyroid surgery: collagen-fibrinogen-thrombin patch versus cellulose gauze-our experience. Surg Res Pract. 2016:2016:3058754.

38. Arnold AC, Sodickson A. Postoperative surgicel mimicking abscesses following cholecystectomy and liver biopsy. Emerg Radiol. 2008:15:183-5.

39. Gao HW, Lin CK, Yu CP, Yu MS, Chen A. Oxidized cellulose (surgicel) granuloma mimicking a primary ovarian tumor. Int J Gynecol Pathol. 2002:21:422-3.

40. Royds J, Kieran S, Timon C. Oxidized cellulose (surgicel) based reaction post thyroidectomy mimicking an abscess: a case report. Int J Surg Case Rep. 2012;3:338-9.

41. Somani BK, Kasthuri RS, Shave RM, Emtage LA. Surgicel granuloma mimicking a renal tumour. Surgery. 2006;139:451.

42. Young ST, Paulson EK, McCann RL, Baker ME. Appearance of oxidized cellulose (surgicel) on postoperative CT scans: similarity to postoperative abscess. AJR Am J Roentgenol. 1993;160:275-7. 